\title{
Review
}

Ophthalmic

Research

Ophthalmic Res 2012;48:43-49

DOI: $10.1159 / 000335982$
Received: October 31, 2011

Accepted after revision: November 30, 2011

Published online: March 6, 2012

\section{Road to Fulfilment: Taming the Immune Response to Restore Vision}

\author{
Andrew D. Dick \\ School of Clinical Sciences and School of Cellular and Molecular Medicine, University of Bristol, Bristol, and \\ National Institute of Health Research-Biomedical Research Centre for Ophthalmology, Moorfields Eye Hospital NHS \\ Foundation Trust and UCL Institute of Ophthalmology, London, UK
}

\section{Key Words}

Experimental auto-immune uveoretinitis - Auto-immune response - Inflammation - Macrophage - Angiogenesis • Auto-immunity

\begin{abstract}
While traditionally considered to be an immune privileged site, the eye, and in particular the retina, is nonetheless endowed with immune-competent cells capable of engaging powerful immune regulatory networks. By understanding the mechanisms that promote immune well-being in the eye, we are able to generate therapies which combat undue immune-mediated damage not only by revealing mechanisms that promote tissue damage, but also by an ability to restore tissue immune homeostasis by harnessing intrinsic immune-regulatory mechanisms. The result is to maintain or restore immune health as well as combat tissue damage evoked during, for example, intra-ocular inflammatory disease (uveitis), angiogenesis (age-related macular degeneration) and retinal degenerative disorders. Immune activation and regulation is a balance that is dictated by cognate and soluble factors at both a tissue and cellular level. These continuously respond to and eradicate danger and pathogenic signals whilst maintaining tissue function by controlling, and not exclusively, vascular barriers, complement activation,
\end{abstract}

macrophage activation and keeping in check local T cell proliferation. Loss of the balance between activation and inhibitory signals leads to uncontrolled tissue damage. Understanding the mechanisms has gained potential therapeutic opportunities not only to suppress on-going inflammation, but also to restore homeostasis and prevent recrudescence.

Copyright $\odot 2012$ S. Karger AG, Basel

\section{The Clinical Need to Suppress Inflammation Goes beyond Uveitis}

Inflammation and immune-mediated pathways result in much of the tissue damage and loss of function which underlie many of the major ophthalmic diseases. This is especially germane to a variety of retinal and choroidal conditions which involve loss or repression of immune regulatory control within the eye secondary to either infection or systemic activation of the immune system and present clinically as uveitis. Not surprisingly, therefore, much of the evidence of suppressing inflammation and pathways involved in immune-mediated damage has arisen from evidence and understanding of mechanisms, both clinically and experimentally, in models of uveitis $[1,2]$. Although we are increasing our understanding of immunopathogenic mechanisms associated with uveitis,

\section{KARGER}

Fax +4161306 1234

E-Mail karger@karger.ch

www.karger.com (c) 2012 S. Karger AG, Basel

$0030-3747 / 12 / 0481-0043 \$ 38.00 / 0$

Accessible online at:

www.karger.com/ore
Prof. Andrew D. Dick

Bristol Eye Hospital

Lower Maudlin Street

Bristol BS1 2LX (UK)

E-Mail a.dick@bristol.ac.uk 
including the interplay between innate and adaptive immunity and the cross-over between auto-inflammatory and auto-immune conditions, there is also a substantial involvement of inflammation in the expression of diabetic retinopathy, age-related macular degeneration and other degenerative conditions, including glaucoma, which remains relatively unexplored.

Our knowledge of effector mechanisms in the generation of auto-immunity, with the breakdown of tolerance to self-antigens, has led to the development of targeted biologic therapy including inhibition of Th1 cells, or more specifically neutralization of the signature effector cytokine TNF $\alpha[3,4]$ and more recently IL-17 [5, 6]. Our understanding of individual susceptibility to disease is also increasing with understanding of gene single nucleotide polymorphisms in key cytokine genes [7-9] as well as HLA-associated genes and genes of unknown function, such as PTPN22 [10], that contribute to whether and when tolerance to self-antigen is broken, as well as the severity of the resulting auto-immune response. Added to this are the rare yet informative genetic polymorphisms or mutations in innate detectors, such as human NOD-like receptors, which display a wide range of disease phenotypes, but characteristically all have recurrent inflammatory episodes and pyrexias, and are termed 'hereditary periodic fevers' [11]. These include characteristic uveitic entities, such as Blau's syndrome, chronic infantile neurological, cutaneous and articular (CINCA) syndrome and indeed auto-inflammation may also be the drive for conditions such as Behçet's disease. In addition, a key to such responses are the interactions which occur with the environment, not just externally but internally via our gastro-intestinal microbiome [12], and with particular reference to promotion or regulation of inflammatory responses in relation of Th17 generation $[13,14]$ and also in enabling a post-thymic regulation which educates the immune system to be tolerant to foreign antigen within our commensal microbiota [15].

There are several theories of what triggers an immune response. Matzinger [16] proposed the 'Danger Theory' where signals from injured host cells signal or set off alarms which activate antigen-presenting cells, whereas the pattern recognition theory proposes that pathogen and microbial (including as discussed above, the gut commensals) elicit activation of the innate immune system through, for example, Toll-like receptors [17]. Finally, the binary theory proposes that regulation or activation of immunity is generated via an integration of signals from cells (which include epithelial cells, platelets, neutrophils and macrophages) derived from both injury and infection [18].
So what is happening at tissue sites? Taking such concepts forward, Medzhitov [19] generated the theory of para-inflammation as a tissue-adaptive response to noxious stress or malfunction, the physiological purpose of which is an attempt to re-establish tissue homeostasis. However, the balance is that if homeostasis is not achieved then the mechanisms evoked become persistent and paradoxically promote further tissue damage. Chen et al. [20] and Xu et al. [21] have addressed this in the context of the pathology we observe in the ageing retina, including evidence of microglial activation and subretinal migration, breakdown of the blood-retinal barrier, complement activation in Bruch's membrane and retinal pigment epithelium cells, and changes in choroidal vasculature (fibrosis) and immune cell phenotype. What breaks a 'normal' para-inflammatory response remains unknown, but the evidence supports a key role for innate immunity as persistent and damaging para-inflammatory responses are observed when there is altered monocyte function, such as in mice which are deficient in chemokine receptor CCR2 [20].

What remains paramount for future success is our need to gain information at the level of individual immune responses and further understanding of environmental influences on gene function to generate more successful and targeted therapies. Hence, the creation of a clear individual immunophenotype will in turn, for example, define prognosis and most importantly direct, as well as predict, response to treatment [22]. For example, the advent of genome-wide technologies to interrogate cell subset transcriptomes has already established signatures which predict prognosis [23]. With such platforms, we can create a dialogue and reciprocity of information between human and animal experimental models. By adopting this combined approach (fig. 1), we can hone our interrogation of several chorioretinal disorders to improve our future treatments of common blinding disorders, including neovascular diseases, inflammation (uveitis), diabetic retinopathy and degenerative disorders (age-related macular degeneration and glaucoma).

\section{The Retina and Myeloid Cells: Friendly Interactions to Maintain Immune Competence}

Within the retina there are immune-competent cells derived from the bone marrow [24-26] which regulate immune health within the tissue to maintain tissue (neuronal) function [27-30]. The ability to maintain neuronal homeostasis, and keep in check danger or pathogenic sig- 
Fig. 1. Schematic illustrating the reciprocity between experimental models, which enable us to dissect and illuminate potential immune mechanisms, and human studies, which, with the advent of genomic and bioinformatic technologies, are generating new insights into immune phenotype and function. Both approaches inform the progress of each other.

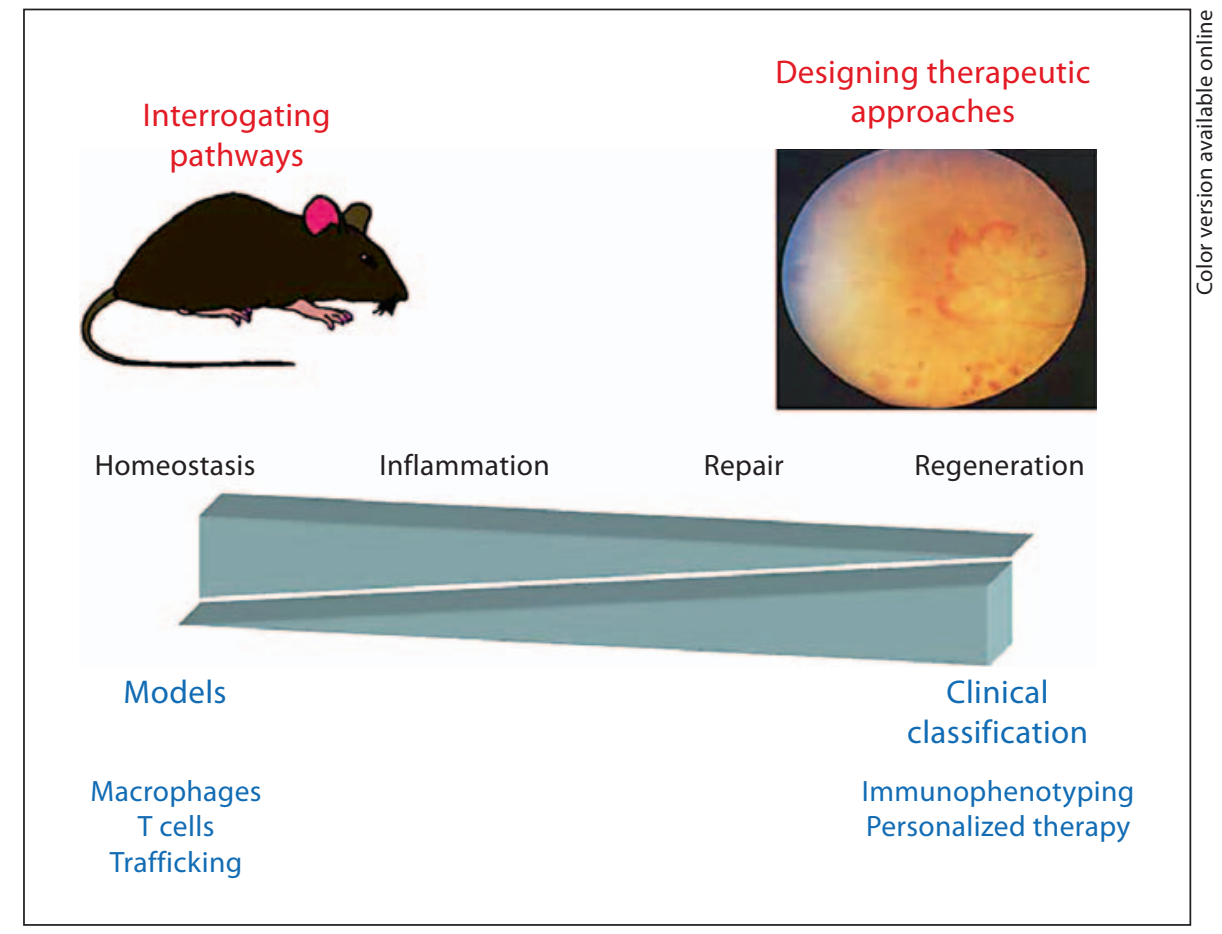

nals, requires a fine balance as dysregulation will promote inadvertent tissue damage. Notwithstanding, the evidence is that microglia preserve a response to both Toll-like receptor ligation or cytokine stimulation (interferon- $\gamma$, IFN- $\gamma$ ) that promotes a predominant anti-inflammatory IL-10 response [31-33], and an ability to migrate to sites of injury/damage whilst maintaining the ability to phagocytose; a much needed scavenger response. The overarching aim and function of microglia is therefore to be able to control inflammation and reduce collateral damage.

\section{Microglia, Turnover, Phenotype and Function}

The question as to whether microglia are long-term residents of the retina and central nervous system has been resolved following recent data using GFP reporter mice that demonstrate that there is a constant turnover of these cells [26]. The question as to whether they contribute to the initiation of inflammation and/or perpetuation of inflammatory responses is also continuously under scrutiny. Whilst we show that the principal default response of retinal microglia is mostly regulatory (IL-10 production, phagocytosis and poor antigen presentation) $[31,32]$, others have shown that microglia potentially con- tribute to the initiation of inflammation [34]. However, using a combination of parabiosis and myeloablation techniques, it was shown most recently that infiltrating myeloid cells during inflammation within the central nervous system contribute to both the initiation and progression of disease (in this case experimental auto-immune encephalomyelitis), and moreover, infiltrating cells do not contribute to the resident pool of microglia during disease [35]. If we look at all concepts and data together, one paradigm that emerges is that microglia remain the sentinel cell population that govern and regulate immune health within the tissue, whilst in extremes, where systemic inflammatory responses drive tissue-specific inflammation, the activated infiltrating cells orchestrate the initiation and perpetuation of inflammatory responses. Whilst this is defensible to some extent for auto-immune or auto-inflammatory disorders (uveitis), we still need to explain under what circumstances, if at all, microglia-mediated tissue control is dysregulated to permit ongoing para-inflammatory-induced tissue damage, which is seen most commonly during degeneration or angiogenesis.

Control of myeloid cells is mediated by a close interaction between both cognate as well as cytokine signals, the understanding of which has generated a categorization of macrophage phenotype-function [36-38]. Macrophages 
are highly adaptable cells which are conditioned and respond to signals in the environment they encounter. We have shown in experimental auto-immune uveoretinitis (EAU) $[39,40]$ that during the course of disease, retinal infiltrating monocyte/macrophage populations display significant phenotype and functional differences. That is, during the peak of disease and tissue destruction, macrophages are activated (classical activation) by TNF-dependent IFN- $\gamma$ stimulation that generates a pro-inflammatory NOS2+ macrophage response (so-called M1 macrophages), contributing to tissue destruction [41], whereas during resolution of inflammation, as observed in the rat model, macrophages demonstrate alternative activation (Arg-1+, M2 macrophages) with a corresponding phenotype and function, which promotes healing [41]. Understanding the pathways which generate or inhibit each form of macrophage will enable us to better design therapeutic approaches for the future.

Why are microglia able to regulate and marshal immune responses? CD200 is a ligand that is highly expressed on neurons and widespread in the retina [42]. Its cognate receptor, CD200 receptor (CD200R) is predominantly expressed by myeloid cells, including microglia [43]. The receptor signals to down-regulate macrophage function [43-46]. Therefore, there remains in-built control against unwanted pro-inflammatory activation of myeloid cells, which we corroborated in human microglia, showing that CD200R ligation maintains retinal microglial ability to migrate and regulate [33]. If, as is currently understood, we wish to restore homeostasis, and given the notion that the most harm is generated via infiltrating cells [35], then we may be able to address this by augmenting natural homeostatic mechanisms. The evidence suggests this is the case, as when the CD200R agonist monoclonal antibody is administered either systemically or locally (intravitreal route), EAU is attenuated [47]. When a similar approach is taken by reconstituting the principal regulatory cytokine released from microglia, IL-10, via gene therapy, again EAU is suppressed [48].

A mechanistic overlap at tissue sites between para-inflammation and (auto)-inflammation in the retina and choroid is revealed through complement activation [4951]. In the ageing retina there is increased complement activation with negative regulation of complement components by oxidative stress and pro-inflammatory cytokines $[52,53]$, principally at the level of the retinal pigment epithelium. Further, no matter what the initial stimulus, macrophages may be activated via their C5a receptor following cleavage of C5 during complement activation. This can be exploited therapeutically by inhibit- ing C5 cleavage with a monoclonal antibody (BB5.1), which when administered either locally (intravitreal route) or systemically suppresses both EAU [54] and laser-induced choroidal neovascularization (CNV) [Liu et al., pers. commun.].

\section{Experimental Models Highlighting Mechanisms and Pathways to Restore Immune Health}

The debate thus far has been centred on the ability to harness mechanisms to restore homeostasis and suppress inflammation during auto-immune inflammation. As discussed, many of the conditions we treat are potentially the result of para-inflammation, including uveitis, which at the time we need to institute treatment is in its intractable, persistent phase (where clinical inflammation is less apparent, but tissue-damaging effects of cell loss and vascular damage are apparent). This is supported by recent data which show that in the persistent phases of EAU, angiogenic responses are pronounced in the absence of obvious inflammation [55]. Nevertheless, we know, despite clinical features of resolution, that the retina remains infiltrated with leucocytes $[39,40,56]$. During the evolution of retinal angiogenesis following acute phases of uveitis in EAU, there remains significant infiltration of arginase-1+ VEGF+ macrophages up to 120 days after immunization. Whether such findings are secondary to para-inflammation or maintained low grade inflammation from infiltrating cells has yet to be resolved. Nevertheless, we do know that removing a pathway of local control of angiogenesis via deletion of a matricellular protein, thrombospondin-1, accentuates the neovascular response, whereas in the absence of a pivotal chemokine for macrophage recruitment, CCR2, diminished angiogenic responses are observed. Such data point toward an inability to restore tissue homeostasis and suggest that damage is persistent as a result of continually recruited cells.

The role macrophages play with respect to the control of vascular barrier and angiogenic responses has been actively investigated $[57,58]$. The quandary is the fundamental understanding of mechanisms that govern macrophage responses in this regard. One notion is that with age, upregulation of IL-10 and downregulation of FasL contribute to regulation of abnormal vascular growth in laser-induced CNV. However, despite the finding that loss of IL-10 reduces the extent of laser-induced CNV, does this make IL-10 an attractive target for therapy? Angiogenic or anti-angiogenic function of macrophages is 
dependent upon how macrophages are activated. Whilst IFN- $\gamma$ and LPS may generate NOS2+VEGF+ M1 macrophages, $\mathrm{PGE}_{2}$ remains a more potent stimulus generating Arg-1+ VEGF+ M2+ macrophages [59]. Whilst IL-10 inhibits the M1 VEGF production, IL-10 fails to inhibit the M2 VEGF production and, moreover, fails to suppress VEGF production in hypoxic conditions [59]. Consequently, therapies (directly or indirectly) to suppress macrophage activation that result in IL-10 generation may result in support of CNV. However, when macrophages are stimulated with IL-4 or IL-13 to generate Arg- $1^{+}$M2 macrophages, VEGF is reduced and large quantities of sFlt-1 are generated [Wu et al., pers. commun.] (fig. 2). In all, the contribution of 'inflammation' in terms of macrophage infiltration is dependent upon the signals the cell will receive and the extent of tissue hypoxia. Dissecting such mechanisms will illuminate more specific pathways to prevent neovascular-associated tissue damage.

\section{Prevent Entry of Cells}

If we continue a tenet that most damage incurred is secondary to the maintenance of infiltrating cells, which in turn may prevent homeostatic redress (sustain parainflammation), then one aspect of therapy is to prevent infiltration of cells to the target site. To this end we noted that when we used FTY720 (Novartis) to prevent principally $\mathrm{T}$ cell, but also myeloid cell, migration to inflammatory sites by down-regulating the expression of sphingosine-1 phosphatase receptor required to permit egress of cells from secondary lymphoid tissue, the inflamed retina became rapidly devoid of infiltrating cells [60]. Taking this further, we noted in EAU that the reduction in infiltrating retinal cells occurred at clinically relevant therapeutic doses of FTY720 over a 24-hour period without direct alteration to the vascular barrier, demonstrating the potential to use this as a potent rescue therapy [Copland et al., in press]. Moreover, this effect was not segregated to the T cell compartment as, either directly or indirectly, myeloid cell and activation within the tissue was also suppressed.

\section{Conclusions}

Immune responses are either the direct cause or underpin the pathology we observe in many of the chorioretinal disorders we currently attempt to treat. Under-

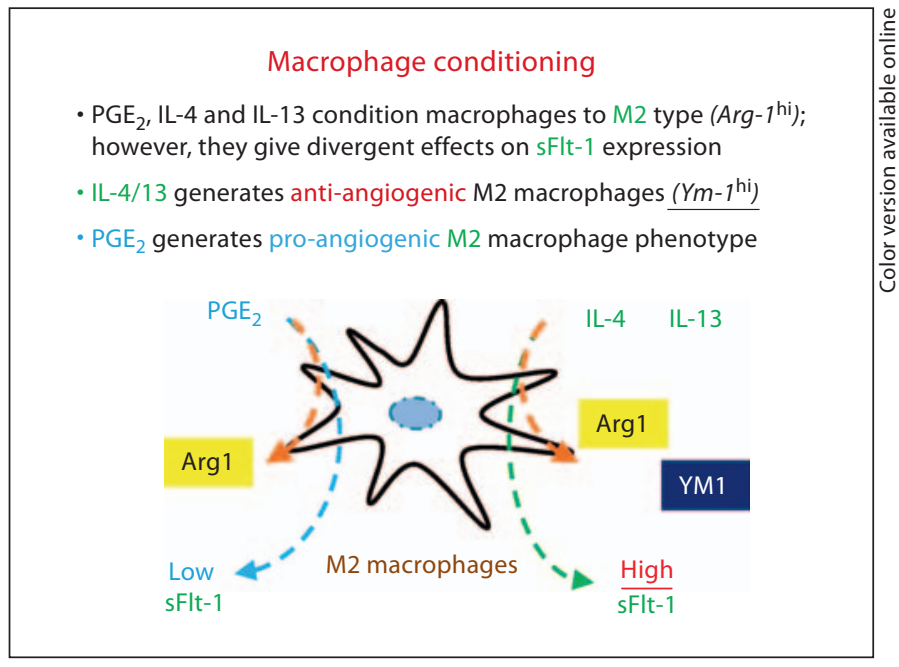

Fig. 2. Schematic represents the effect of macrophage conditioning stimuli on phenotype and function in relation to angiogenesis.

standing the pathology and mechanisms will contribute to development of therapies to either counter directly the inflammatory response, such as in uveitis, or assist in prevention of recurrence by redressing homeostasis, orchestrated by maintaining tissue immune health. Together with the increasing ability and potential to use genome-wide technologies to individualize diagnosis and treatment we are entering an era of not just stratifying patients groups but predicting individual responses and instituting appropriate and targeted therapy (personalized medicine). Together with understanding immune health through, for example understanding microglial behaviour, the role of complement and trafficking and activation of immune cells, novel therapeutics will be translated appropriately and to greater effect over the next decade.

\section{Acknowledgements}

This work was presented as the Ophthalmic Research Lecture at European Vision and Eye Research Association annual meeting in Crete, 2011. Work presented is supported from grants awarded by Dunhill Medical Trust and National Eye Research Centre and Underwood Trust. FTY270 work was supported by an investigator grant from Institutes of Novartis BioMedical Research. I am indebted to Dr. Richard Lee for critical reading of the manuscript.

Ophthalmic Res 2012;48:43-49 


\section{References}

$>1$ Forrester JV: Privilege revisited: an evaluation of the eye's defence mechanisms. Eye (Lond) 2009;23:756-766.

$\checkmark 2$ Forrester JV, Xu H, Lambe T, Cornall R: Immune privilege or privileged immunity? $\mathrm{Mu}$ cosal Immunol 2008;1:372-381.

$>3$ Imrie FR, Dick AD: Biologics in the treatment of uveitis. Curr Opin Ophthalmol 2007; 18:481-486.

4 Sharma SM, Nestel AR, Lee RW, Dick AD: Clinical review: anti-TNF- $\alpha$ therapies in uveitis: perspective on 5 years of clinical experience. Ocul Immunol Inflamm 2009;17: 403-414.

$>5$ Chi W, Zhu X, Yang P, Liu X, Lin X, Zhou H, et al: Upregulated IL-23 and IL-17 in Behçet patients with active uveitis. Invest Ophthalmol Vis Sci 2008;49:3058-3064.

6 Ke Y, Liu K, Huang GQ, Cui Y, Kaplan HJ, Shao H, et al: Anti-inflammatory role of IL17 in experimental autoimmune uveitis. J Immunol 2009;182:3183-3190.

$>7$ Atan D, Fraser-Bell S, Plskova J, Kuffova L, Hogan A, Tufail A, et al: Cytokine polymorphism in noninfectious uveitis. Invest Ophthalmol Vis Sci 2010;51:4133-4142.

$>8$ Atan D, Fraser-Bell S, Plskova J, Kuffova L, Hogan A, Tufail A, et al: Punctate inner choroidopathy and multifocal choroiditis with panuveitis share haplotypic associations with IL10 and TNF loci. Invest Ophthalmol Vis Sci 2011;52:3573-3581.

$\checkmark 9$ Mizuki N, Meguro A, Ota M, Ohno S, Shiota T, Kawagoe T, et al: Genome-wide association studies identify IL23R-IL12RB2 and IL10 as Behçet's disease susceptibility loci. Nat Genet 2010;42:703-706

>10 Burn GL, Svensson L, Sanchez-Blanco C, Saini M, Cope AP: Why is PTPN22 a good candidate susceptibility gene for autoimmune disease? FEBS Lett 2011:585:36893698.

11 McDermott MF: Genetic clues to understanding periodic fevers, and possible therapies. Trends Mol Med 2002;8:550-554.

$>12$ Scher JU, Abramson SB: The microbiome and rheumatoid arthritis. Nat Rev Rheumatol 2011;7:569-578.

- 13 Esplugues E, Huber S, Gagliani N, Hauser AE, Town T, Wan YY, et al: Control of TH17 cells occurs in the small intestine. Nature 2011;475:514-518.

${ }_{14}$ Kriegel MA, Sefik E, Hill JA, Wu HJ, Benoist C, Mathis D: Naturally transmitted segmented filamentous bacteria segregate with diabetes protection in nonobese diabetic mice. Proc Natl Acad Sci USA 2011;108: 11548-11553.

15 Lathrop SK, Bloom SM, Rao SM, Nutsch K, Lio CW, Santacruz N, et al: Peripheral education of the immune system by colonic commensal microbiota. Nature 2011;478:250 254.
16 Matzinger P: The danger model: a renewed sense of self. Science 2002;296:301-305.

-17 Medzhitov R, Janeway CA Jr: Decoding the patterns of self and nonself by the innate immune system. Science 2002;296:298-300.

18 Nathan C: Neutrophils and immunity: challenges and opportunities. Nat Rev Immunol 2006;6:173-182.

19 Medzhitov R: Origin and physiological roles of inflammation. Nature 2008;454:428-435.

20 Chen M, Forrester JV, Xu H: Dysregulation in retinal para-inflammation and age-related retinal degeneration in CCL 2 or CCR 2 deficient mice. PLoS One 2011;6:e22818.

$21 \mathrm{Xu} \mathrm{H}$, Chen M, Forrester JV: Para-inflammation in the aging retina. Prog Retin Eye Res 2009;28:348-368.

22 Lee RW, Schewitz LP, Nicholson LB, Dayan CM, Dick AD: Steroid refractory CD4+ T cells in patients with sight-threatening uveitis. Invest Ophthalmol Vis Sci 2009;50 4273-4278.

23 McKinney EF, Lyons PA, Carr EJ, Hollis JL, Jayne DR, Willcocks LC, et al: A CD8+ T cell transcription signature predicts prognosis in autoimmune disease. Nat Med 2010;16:586591, 1 p following 591.

24 Forrester JV, Xu H, Kuffova L, Dick AD, McMenamin PG: Dendritic cell physiology and function in the eye. Immunol Rev 2010;234: 282-304

25 Kezic J, Xu H, Chinnery HR, Murphy CC, McMenamin PG: Retinal microglia and uveal tract dendritic cells and macrophages are not CX3CR1 dependent in their recruitment and distribution in the young mouse eye. Invest Ophthalmol Vis Sci 2008;49:1599-1608.

$26 \mathrm{Xu} \mathrm{H}$, Chen M, Mayer EJ, Forrester JV, Dick AD: Turnover of resident retinal microglia in the normal adult mouse. Glia 2007;55:11891198 .

-27 Balasubramaniam B, Carter DA, Mayer EJ, Dick AD: Microglia derived IL-6 suppresses neurosphere generation from adult human retinal cell suspensions. Exp Eye Res 2009; 89:757-766

28 Dick AD: Influence of microglia on retinal progenitor cell turnover and cell replacement. Eye (Lond) 2009;23:1939-1945.

29 Dick AD, Carter D, Robertson M, Broderick C, Hughes E, Forrester JV, et al: Control of myeloid activity during retinal inflammation. J Leukoc Biol 2003;74:161-166.

30 Ransohoff RM, Cardona AE: The myeloid cells of the central nervous system parenchyma. Nature 2010;468:253-262.

31 Broderick C, Duncan L, Taylor N, Dick AD: IFN-gamma and LPS-mediated IL-10-dependent suppression of retinal microglial activation. Invest Ophthalmol Vis Sci 2000;41: 2613-2622.
-32 Carter DA, Dick AD: Lipopolysaccharide/ interferon- $\gamma$ and not transforming growth factor- $\beta$ inhibits retinal microglial migration from retinal explant. Br J Ophthalmol 2003;87:481-487.

33 Carter DA, Dick AD: CD200 maintains microglial potential to migrate in adult human retinal explant model. Curr Eye Res 2004;28: 427-436.

34 Rao NA, Kimoto T, Zamir E, Giri R, Wang R, Ito $S$, et al: Pathogenic role of retinal microglia in experimental uveoretinitis. Invest Ophthalmol Vis Sci 2003;44:22-31.

-35 Ajami B, Bennett JL, Krieger C, McNagny KM, Rossi FM: Infiltrating monocytes trigger EAE progression, but do not contribute to the resident microglia pool. Nat Neurosci 2011;14:1142-1149.

36 Gordon S: Alternative activation of macrophages. Nat Rev Immunol 2003;3:23-35.

37 Gordon S, Taylor PR: Monocyte and macrophage heterogeneity. Nat Rev Immunol 2005;5:953-964.

38 Murray PJ, Wynn TA: Protective and pathogenic functions of macrophage subsets. Nat Rev Immunol 2011.

39 Copland DA, Wertheim MS, Armitage WJ, Nicholson LB, Raveney BJ, Dick AD: The clinical time-course of experimental autoimmune uveoretinitis using topical endoscopic fundal imaging with histologic and cellular infiltrate correlation. Invest Ophthalmol Vis Sci 2008;49:5458-5465.

40 Kerr EC, Raveney BJ, Copland DA, Dick AD, Nicholson LB: Analysis of retinal cellular infiltrate in experimental autoimmune uveoretinitis reveals multiple regulatory cell populations. J Autoimmun 2008;31:354-361.

41 Robertson MJ, Erwig LP, Liversidge J, Forrester JV, Rees AJ, Dick AD: Retinal microenvironment controls resident and infiltrating macrophage function during uveoretinitis. Invest Ophthalmol Vis Sci 2002;43: 2250-2257.

42 Dick AD, Broderick C, Forrester JV, Wright GJ: Distribution of OX2 antigen and OX 2 receptor within retina. Invest Ophthalmol Vis Sci. 2001;42:170-176.

-43 Hoek RM, Ruuls SR, Murphy CA, Wright GJ, Goddard R, Zurawski SM, et al: Down-regulation of the macrophage lineage through interaction with OX2 (CD200). Science 2000; 290:1768-1771.

44 Banerjee D, Dick AD: Blocking CD200CD200 receptor axis augments NOS-2 expression and aggravates experimental autoimmune uveoretinitis in Lewis rats. Ocul Immunol Inflamm 2004; 12:115-125

45 Broderick C, Hoek RM, Forrester JV, Liversidge J, Sedgwick JD, Dick AD: Constitutive retinal CD200 expression regulates resident microglia and activation state of inflammatory cells during experimental autoimmune uveoretinitis. Am J Pathol 2002;161:16691677. 
46 Jenmalm MC, Cherwinski H, Bowman EP, Phillips JH, Sedgwick JD: Regulation of myeloid cell function through the CD200 receptor. J Immunol 2006;176:191-199.

-47 Copland DA, Calder CJ, Raveney BJ, Nicholson LB, Phillips J, Cherwinski $\mathrm{H}$, et al: Monoclonal antibody-mediated CD200 receptor signaling suppresses macrophage activation and tissue damage in experimental autoimmune uveoretinitis. Am J Pathol 2007;171:580-588.

48 Broderick CA, Smith AJ, Balaggan KS, Georgiadis A, Buch PK, Trittibach PC, et al: Local administration of an adeno-associated viral vector expressing IL-10 reduces monocyte infiltration and subsequent photoreceptor damage during experimental autoimmune uveitis. Mol Ther 2005;12:369-373.

49 Ferrara DC, Merriam JE, Freund KB, Spaide RF, Takahashi BS, Zhitomirsky I, et al: Analysis of major alleles associated with age-related macular degeneration in patients with multifocal choroiditis: strong association with complement factor $\mathrm{H}$. Arch Ophthalmol 2008;126:1562-1566.
50 Hageman GS, Anderson DH, Johnson LV, Hancox LS, Taiber AJ, Hardisty LI, et al: A common haplotype in the complement regulatory gene factor $\mathrm{H}(\mathrm{HF} 1 / \mathrm{CFH})$ predisposes individuals to age-related macular degeneration. Proc Natl Acad Sci USA 2005; 102:72277232 .

51 Klein RJ, Zeiss C, Chew EY, Tsai JY, Sackler RS, Haynes C, et al: Complement factor $\mathrm{H}$ polymorphism in age-related macular degeneration. Science 2005;308:385-389.

52 Chen M, Muckersie E, Luo C, Forrester JV, $\mathrm{Xu} \mathrm{H}$ : Inhibition of the alternative pathway of complement activation reduces inflammation in experimental autoimmune uveoretinitis. Eur J Immunol 2010;40:2870-2881.

53 Chen M, Muckersie E, Robertson M, Forrester JV, Xu H: Up-regulation of complement factor $\mathrm{B}$ in retinal pigment epithelial cells is accompanied by complement activation in the aged retina. Exp Eye Res 2008;87:543550 .

54 Copland DA, Hussain K, Baalasubramanian S, Hughes TR, Morgan BP, Xu H, et al: Systemic and local anti-C5 therapy reduces the disease severity in experimental autoimmune uveoretinitis. Clin Exp Immunol 2010; 159:303-314.
55 Chen M, Copland DA, Zhao J, Liu J, Forrester JV, Dick AD, et al: Persistent inflammation subverts thrombospondin-1-induced regulation of retinal angiogenesis and is driven by CCR2 ligation. Am J Pathol 2011.

56 Kerr EC, Copland DA, Dick AD, Nicholson LB: The dynamics of leukocyte infiltration in experimental autoimmune uveoretinitis. Prog Retin Eye Res 2008;27:527-535.

57 Apte RS, Richter J, Herndon J, Ferguson TA: Macrophages inhibit neovascularization in a murine model of age-related macular degeneration. PLoS Med 2006;3:e310.

58 Kelly J, Ali Khan A, Yin J, Ferguson TA, Apte RS: Senescence regulates macrophage activation and angiogenic fate at sites of tissue injury in mice. J Clin Invest 2007;117:34213426.

59 Wu WK, Llewellyn OP, Bates DO, Nicholson LB, Dick AD: IL-10 regulation of macrophage VEGF production is dependent on macrophage polarisation and hypoxia. Immunobiology 2010;215:796-803.

60 Raveney BJ, Copland DA, Nicholson LB, Dick AD: Fingolimod (FTY720) as an acute rescue therapy for intraocular inflammatory disease. Arch Ophthalmol 2008;126:13901395. 